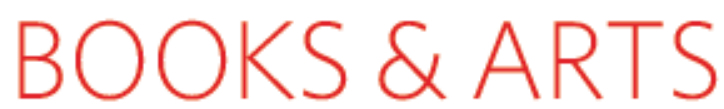

\title{
In the grey zone
}

If behaviour arises from interactions between genes and the environment, in what sense is it hardwired?

\author{
Hardwired Behavior: What Neuroscience \\ Reveals about Morality \\ by Laurence R. Tancredi \\ Cambridge University Press: 2005. 250 pp. \\ $\$ 28.99$
}

\section{Erik Parens}

We seem beset by an instinct to make binary oppositions: either our choices are free or they are hardwired; we are shaped by either nurture or nature; mental processes are important or physical processes are; morality is a social construct or it is biological in origin. Yet one of the most remarkable things about animals like us is that we can see those binary oppositions for what they are. We can understand why these 'either or's are wholly inadequate for understanding the phenomena at hand.

Laurence Tancredi's book Hardwired Behavior powerfully presents science that shows the gross inadequacy of the binary terms we often use to talk about the genesis and character of complex human behaviours. He writes: "Our brain structures are not immutable; they are susceptible to change for the better and change for the worse." Indeed, much of the research he discusses rests on this neuroplasticity. $\mathrm{He}$ reports on research showing that talk therapy can produce neuronal changes. His chapter on gender differences suggests that changing social conceptions of the roles of women "will inevitably affect the biology of their brains over time. He reports on research showing that rats deprived of nurture at birth fail to express a gene that is correlated with their ability to handle stress. And he refers several times to a fascinating study by Avshalom Caspi and colleagues (Science 301, 386-389; 2002), which found that the likelihood of children becoming antisocial as adults is a function of both their genomes and their experiences. As Tancredi observes, this finding "emphasizes the interactive nature of genes and environment, nature and nurture".

Why then did Tancredi call his book Hardwired Behavior? Because he wants to underscore that those interactions between genes and the environment result in brains with strong dispositions. He also wants to convey the excitement surrounding scientific and technological advances that enable researchers to glimpse the neural correlates of those dispositions. Moreover, as a lawyer and a psychiatrist, he wants to show that the more we understand

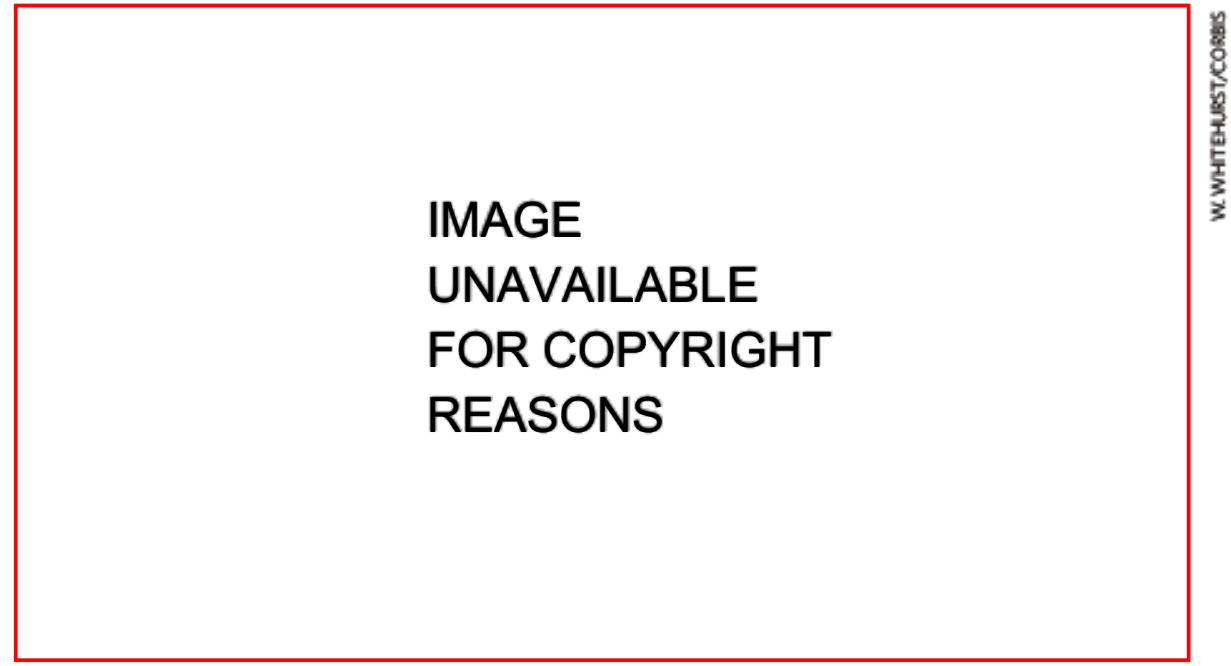

Slaves to biology: do our genes and the environment remove our freedom to control our own behaviour?

the neurobiology of those dispositions, the less we should believe that individuals are as free to choose as judges and moralists may assume.

So, for example, he describes the horrific childhood environment of the murderer Ricky Green and, invoking the Caspi study, speculates about Green's genotype. His primary point is that Green's experience altered the biology of his brain. He wants us to appreciate the "deeply physical nature of Green's dispositions as an adult. This point is in a sense more profound than it may seem. If one believed that human choices originate in a metaphysical soul, in an entity beyond nature, then it would come as a great surprise to learn that human choices emerge out of staggeringly complex interactions within and between biological and social systems. But if one long ago gave up the idea of a metaphysical soul, the point about the deeply physical nature of our behaviours seems less profound and is potentially misleading.

Consider Tancredi's account of his patient Art, whose "biologically compelled" sexual escapades destroyed his relationship with his fiancée. After the break-up and several months of psychotherapy, Art entered a new relationship. He admitted that he still had the urge to get involved with other women, but this time around he could admit that he had these feelings. " He knew it would be a long and at times rocky road to having a truly successful relationship, but he was now committed to make this happen."
Art's sexual escapades and his commitment to stop them are both deeply physical in the broad sense that he couldn't experience them if his genes and neurons weren't working exactly as they were. But leaving aside rare cases where a single genetic mutation or brain lesion causes an aberrant behaviour, much less is known about the causal pathways that lead to complex human behaviours than this “deeply physical ${ }^{\circledR}$ language seems to suggest. Moreover, when more is known about these causal pathways, the essential elements will be not just genes and neurons, but also words, human relationships and social customs.

To the extent that this "deeply physical" language seduces us into thinking that our behaviour is hardwired - in the sense of being determined by genes and neurons alone - it is deeply unhelpful. To the extent that it reminds us that our choices don't arise in the way the metaphysical model suggests, it is helpful. And to the extent that it is an expression of the desire to move from condemning bad behaviours to understanding them, it is deeply generous.

Thinking entails noticing when we have allowed the instinct for binaries to keep us from the complexity of the phenomena at hand. In much of Hardwired Behavior, Tancredi helps us get over that instinct, and for that we should be grateful.

Erik Parens is at The Hastings Center,

21 Malcolm Gordon Drive, Garrison,

New York 10524-5555, USA. 